Journal of Data Science 1(2003), 313-336

\title{
Analysis of Bank Failure Using Published Financial Statements: The Case of Indonesia (Part 2)
}

\author{
Loso Judijanto and E. V. Khmaladze ${ }^{1}$ \\ University of New South Wales
}

Abstract: Published financial statement is the only publicly available report on financial condition of a bank operating in Indonesia. It contains limited information, but we want to exploit it to discriminate between normal, problem, and liquidated banks and to find factors underlying these conditions.

We observed 213 banks and analysed 42 initial variables representing earning and profitability, productivity and efficiency, quality of assets, capital adequacy, growth and aggressiveness, credibility, size, income and source of fund diversification, liquidity, and dependence on affiliates.

In the classification we used ranks of each variable rather than its numerical value as such. After learning the characteristic of variables theoretically, applying certain statistical tests, making necessary transformations, creating new variables and deleting unnecessary variables, we found that the ranks of 12 variables out of initial 42 could discriminate three groups of banks significantly two years before failure while the ranks of just two variables could discriminate significantly one year before failure.

We considered three major groups of variables in our first paper. In this second paper we start with capital adequacy variables and consider altogether six groups of variables.

Then we show that it is sufficient to select seven basic aspects of financial structure and performance of a bank, which can be efficiently and consistently measured by the variables of simple and

\footnotetext{
${ }^{1}$ Currently at Victoria University of Wellington.
} 
clear intuitive meaning (see the list of abbreviations below in the text). These are: efficiency in productivity and earning (ranks of EBT/SE, PM, ROE and ROEA), capital adequacy (ranks of E/EA and E/L), interest gap (ranks of IM and NII/L), credibility (ranks of $\mathrm{ARCF}$ ), liquidity (ranks of LA/D), dependence on affiliates (ranks of NFA/L), and security of earning assets (ranks of PLL/L).

Key words: Bank failure, ranks, higher the better, lower the better.

\section{Introduction}

In the fisrt part of this work (see Judijanto and Khmaladze, 2003) we described our goal: to find, based only on the publicly available reports in Indonesian press, a few variables that will allow to discriminate between different groups of banks and separate ailing banks prior to the failure. In finding these variables we considered 42 variables (see the List of Abbreviations below) representing most sides of activity of a bank. Variables which describe earning and profitability, productivity and efficiency and quality of assets were analysed in the Part 1 . Here we continue with analysis of variables representing capital adequacy, growth and aggressivenes, cost of fund and credibility, size of assets, source of income and diversification and also liquidity and dependence on affiliates (Sections 2.5 - 2.11). Then, in Section 3 we use some correllation and principal components analysis, which eventually will lead us to just 7 variables with quite high discriminating power two years prior to failure, while only two variables can discriminate just one year before the failure (Section 4).

For convenience of reference and reading we preserved the numeration of sections and tables throughout the both parts of this publication. Therefore, here we start with section number 2.5.

\subsection{Capital adequacy variables. equity over assets (E/A)}

A bank should have adequate amount of capital to support the stability and sustainability of its operations. There are three variables which describe what is called a capital adequacy: equity over assets (E/A), equity over 
earning assets (E/EA), and equity over loans (E/L). Indeed as it is preferable for a bank to have high amount of equity, these variables should belong to the HB group.

Logically it seems more correct for us to consider E/EA instead of E/A because in fact only earning assets, which directly generate earning, contain risks to be covered. As $\mathrm{E} / \mathrm{L}$ had been already chosen as a pair with PLL/L for measuring quality of loans (see "Provision for loan losses over equity" of Section 2.4), then we chose E/EA for measuring capital adequacy.

Table 14: Average values and ranks of E/EA

\begin{tabular}{lcccc}
\hline \multicolumn{1}{c}{ Average values } & \multicolumn{2}{c}{ Average ranks } \\
\hline Normal & 1995 & 1996 & 1995 & 1996 \\
Problem & $14.40(0.70)$ & $13.77(0.70)$ & 118.15 & 117.69 \\
Liquidated & $10.09(0.70)$ & $9.10(0.64)$ & 76.12 & 78.26 \\
\hline
\end{tabular}

Remark that the normal banks have significantly highest E/EA among the group of banks (see Table 14), and the banks in both liquidated and problem groups have similar problem in terms of capital adequacy.

\subsection{Growth and aggressiveness variables}

Loans growth rate (LGR). Loans market share increment (LMSI). Deposits growth rate (DGR). Deposits market share increment (DMSI).

First, we introduce few notations: for a time $t$ let

$L_{t}$ be total amount of loans given by a bank,

$L_{t}^{\prime}$ be total amount of loans given by all the other banks,

$D_{t}$ be total amount of deposits at a bank, and

$D_{t}^{\prime}$ be total amount of deposits at all other banks. 
Then the loans growth rate (LGR) is defined as

$$
L G R=\frac{L_{t}-L_{t-1}}{L_{t}}
$$

while the loans-market share increment (LMSI) is defined as

$$
L M S I=\frac{L_{t}}{L_{t}+L_{t}^{\prime}}-\frac{L_{t-1}}{L_{t-1}+L_{t-1}^{\prime}}
$$

Similarly, the deposits growth rate (DGR) is defined as

$$
D G R=\frac{D_{t}-D_{t-1}}{D_{t}}
$$

and the deposits-market share increment (DMSI) is defined as

$$
D M S I=\frac{D_{t}}{D_{t}+D_{t}^{\prime}}-\frac{D_{t-1}}{D_{t-1}+D_{t-1}}
$$

The higher these four variables are the more aggressive the policy of a bank is. However, it is not clear whether to be aggressive all the time is necessarily a good strategy. We would rather share a point of view that this should remain a matter of specific policy within specific circumstances of a bank. Consequently, we think all four variables should be included in the O group.

Empirical data basically supports this prior attitude (see Table 15), but there is one remarkable feature worthy of attention: aggressiveness of liquidated banks on both deposits and loans market is quite high. Apriori there is nothing wrong with this policy, and in many circumstances this would be even very good policy. However, as we will see later (in "Loans to affiliates over loan" of Section 2.11), the structure of loans of liquidated banks was not good ( most of the loans were given to affiliates. This typically implies that the risk associated with such loans is underestimated and their profitability is too low (see NII/L in "Return on loans", Table 3 in particular).

As a bank expands its earning assets, it has to maintain capital adequacy ratio ruled out by the central bank. Even BI had decreed a regulation to increase CAR annually from $8 \%$ in 1996 to $12 \%$ in 2002 . Hence though 
Table 15: Average values and ranks of LGR, LMSI, DGR and DMSI

Loans growth rate

\begin{tabular}{lcccc}
\hline & \multicolumn{2}{c}{ Average values } & \multicolumn{2}{c}{ Average ranks } \\
\hline \multicolumn{1}{c}{ Group } & 1995 & 1996 & 1995 & 1996 \\
\hline Normal & $43.66(4.98)$ & $38.67(4.40)$ & 107.29 & 111.03 \\
Problem & $35.30(5.16)$ & $23.94(3.31)$ & 101.89 & 91.98 \\
Liquidated & $50.53(11.33)$ & $37.06(9.01)$ & 111.94 & 101.84 \\
\hline
\end{tabular}

Loans-market share increment

\begin{tabular}{lcccc}
\hline & \multicolumn{2}{c}{ Average values } & \multicolumn{2}{c}{ Average ranks } \\
\hline \multicolumn{1}{c}{ Group } & 1995 & 1996 & 1995 & 1996 \\
\hline Normal & $0.02(0.01)$ & $0.02(0.01)$ & 106.83 & 105.38 \\
Problem & $-0.12(0.10)$ & $-0.07(0.06)$ & 96.79 & 96.20 \\
Liquidated & $0.07(0.04)$ & $0.12(0.07)$ & 121.52 & 131.30 \\
\hline
\end{tabular}

Deposits growth rate

\begin{tabular}{lcccc}
\hline & \multicolumn{2}{c}{ Average values } & \multicolumn{2}{c}{ Average ranks } \\
\hline \multicolumn{1}{c}{ Group } & 1995 & 1996 & 1995 & 1996 \\
\hline Normal & $49.69(4.96)$ & $39.44(3.30)$ & 108.73 & 109.70 \\
Problem & $35.39(5.25)$ & $30.32(3.79)$ & 94.82 & 95.00 \\
Liquidated & $44.68(7.61)$ & $44.44(9.74)$ & 112.38 & 106.08 \\
\hline
\end{tabular}

Deposits-marcet share increment

\begin{tabular}{lcccc}
\hline & \multicolumn{2}{c}{ Average values } & \multicolumn{2}{c}{ Average ranks } \\
\hline \multicolumn{1}{c}{ Group } & 1995 & 1996 & 1995 & 1996 \\
\hline Normal & $0.02(0.01)$ & $0.02(0.01)$ & 107.52 & 106.22 \\
Problem & $-0.06(0.04)$ & $-0.02(0.03)$ & 96.95 & 90.02 \\
Liquidated & $0.02(0.02)$ & $0.14(0.07)$ & 117.06 & 134.26 \\
\hline
\end{tabular}

earning assets of a bank may be constant, a bank still has to be able to keep up its equity to fulfill increasing CAR demanded by regulation. In so doing, a bank may have additional paid-up capital from its own shareholders, 
make public offering of its shares in stock-exchange, offer its shares to new partners, or retain most of its net income.

\section{Equity growth rate (EGR)}

The empirical data (Table 16) demonstrates that banks from different groups can not be distinguished by this variable. It means that all banks followed regulation on capital adequacy, though we recognized that liquidated and problem banks have the lowest capital adequacy (see Section 2.5). Because of this indiscriminating characteristic, we will not use EGR for further analysis.

\section{Loans over deposits (L/D)}

The $\mathrm{L} / \mathrm{D}$ ratio measures a balance between deposits taking and lending activities of a bank.It is commonly preferable for a bank to have this ratio not too far from $100 \%$. The empirical data shows again that all of three groups can not be distinguished by this variable. The low level of discriminatory power suggests us to delete this variable for analysis.

\section{Table 16: Average values and ranks of EGR and L/D}

Equity growth rate

\begin{tabular}{|c|c|c|c|c|}
\hline & \multicolumn{2}{|c|}{ Average values } & \multicolumn{2}{|c|}{ Average ranks } \\
\hline Group & 1995 & 1996 & 1995 & 1996 \\
\hline Normal & $35.98(8.20)$ & $32.36(6.07)$ & 107.74 & 104.52 \\
\hline Problem & $24.33(6.22)$ & $28.55(4.62)$ & 104.17 & 121.36 \\
\hline Liquidated & $25.75(5.63)$ & $44.40(13.10)$ & 106.18 & 103.42 \\
\hline \multicolumn{5}{|c|}{ Loans/deposits } \\
\hline & \multicolumn{2}{|c|}{ Average values } & \multicolumn{2}{|c|}{ Average ranks } \\
\hline Group & 1995 & 1996 & 1995 & 1996 \\
\hline Normal & $143.53(12.44)$ & $144.93(13.72)$ & 108.76 & 106.46 \\
\hline Problem & $99.59(7.38)$ & $94.84(4.98)$ & 102.77 & 108.62 \\
\hline Liquidated & $98.05(8.06)$ & $94.56(5.99)$ & 101.66 & 108.22 \\
\hline
\end{tabular}




\subsection{Cost of fund as a credibility measurement of a bank}

It is commonly accepted that one can use cost of fund to measure credibility of a bank. If a bank pays relatively lower interest to funds received than other banks, it means that the bank is perceived as a more secure and trustworthy than other banks. Hence cost of fund variable should have the LB characteristic.

In measuring cost of fund, one can consider either IE/D or IE/TPF. We chose IE/TPF as it is more reasonable and proper (see "Interest margin. ..." of Section 2.2). The empirical data also supports this choice as IE/TPF demonstrates LB character more consistently than IE/D (compare data in Table 17).

\subsection{Size of assets variable}

The range of assets among existing banks is so wide that the only natural way to visualize them on a graph is to use logarithmic scale. Denote $A_{(i)}$ the $i$-th largest assets. The Figure 8.1 below shows the points $\ln A_{(i)}$ against $i$.

First conclusion that follows from the graph is that there is no relationship between the size of assets and performance of banks. Nothing of the kind like "smaller banks perform worse" or "larger banks perform better" is true. Hence we can not use $A_{(i)}$ as discriminatory variable.

Second conclusion is that the graph demonstrates another curious feature - in its main body the data agrees well with so-called Zipf-Mandelbrott Law (see, e.g., Khmaladze(2001):

$$
\ln A_{(i)} \approx a+b i
$$

This law is very famous in the analysis of very versatile sort of data - for example, of frequencies of words in literary texts (see, e.g., Baayen(2001). If $\nu_{(i)}$ denotes $i$-th largest frequency of a word in a given text, then $\ln \nu_{(i)}$ frequently agrees well with

$$
\ln \nu_{(i)}=a+b i
$$

Deviation from this linearity occurs for very small frequencies and also for very large frequencies, just similar to what we observe for assets $A_{(i)}$. 
Table 17: Average values and ranks of IE/D

Interest expenses

\begin{tabular}{lcccc}
\hline & \multicolumn{2}{c}{ Average values } & \multicolumn{2}{c}{ Average ranks } \\
\hline \multicolumn{1}{c}{ Group } & 1995 & 1996 & 1995 & 1996 \\
\hline Normal & $17.35(1.26)$ & $18.42(1.94)$ & 103.67 & 102.92 \\
Problem & $14.31(1.17)$ & $14.06(0.96)$ & 107.26 & 102.17 \\
Liquidated & $15.76(0.90)$ & $16.77(0.10)$ & 127.30 & 138.70 \\
\hline
\end{tabular}

Interest expenses/third party funds

\begin{tabular}{lcccc}
\hline \multicolumn{1}{c}{ Average values } & \multicolumn{2}{c}{ Average ranks } \\
\hline \multicolumn{1}{c}{ Group } & 1995 & 1996 & 1995 & 1996 \\
\hline Normal & $9.99(0.29)$ & $10.28(0.30)$ & 99.36 & 98.28 \\
Problem & $11.01(0.56)$ & $11.23(0.56)$ & 117.95 & 114.65 \\
Liquidated & $12.22(0.48)$ & $13.50(0.59)$ & 139.90 & 150.98 \\
\hline
\end{tabular}

We deleted IE/D and used IE/TPF for further analysis.

More detailed analysis of this graph is very interesting, but lies beyond the scope of the present report.

\subsection{Sources of income and funds diversification variables}

Dependence on single type of income source and on single type of fund source may be considered as not a good practice as this practice is relatively more viable to change in market conditions. It should be considered good for a bank to be able to generate fee-based income from activities like arranging syndicated loans, credit card administration, trade finance administration, payment agent, or collection agent, as they are relatively risk-less activities. Also, it should be considered good if a bank does not depend solely on deposits and can diversify its source of funds, for instance, by issuing marketable securities or receiving low-interest off-shore loans.

We will use non-interest income over operating income (NonII/OI) ratio as a measure of diversification in sources of income and deposits over thirdparty funds $(\mathrm{D} / \mathrm{TPF})$ ratio as a measure of dependence on deposits as a source of funds. 


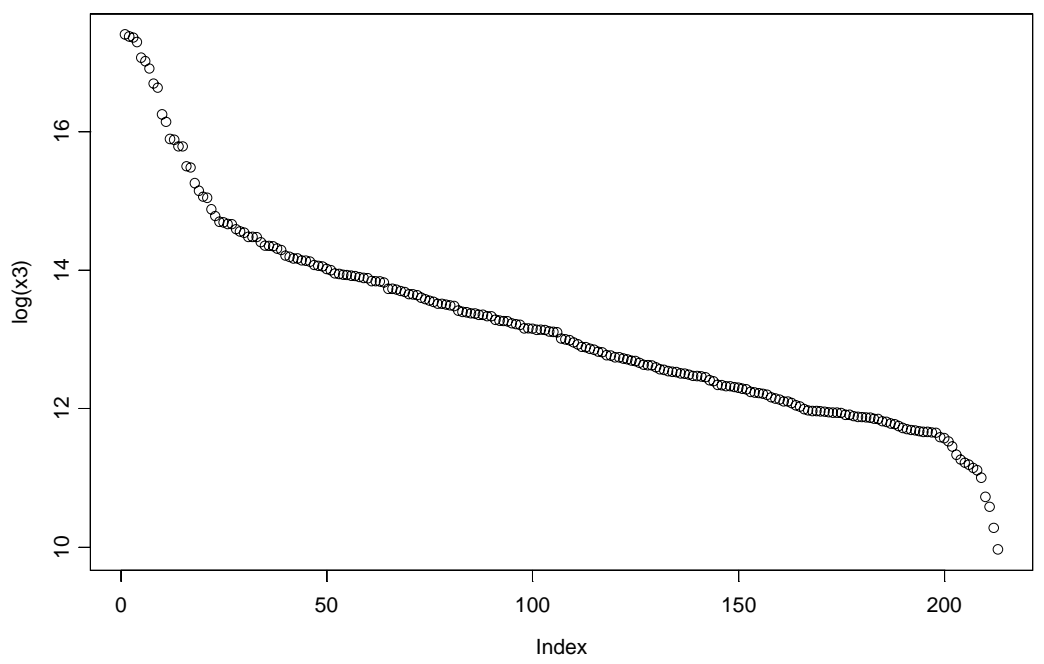

Figure 11: $\log A(i)$ against $i$.

The empirical data indicates that all groups of banks can not be distinguished by both variables. The low level of discriminatory power makes us delete both variables.

A bank should keep sufficient amount of its assets in liquid assets in case of hugely and abruptly withdrawal of deposits . Liquid assets can be in the forms of cash in vault, current account at other banks, current account at BI, or marketable securities.

The LA/D variable measures the proportion of deposits which can be repaid promptly if there is a run on that bank. Indeed, the higher this ratio the better bank is. Empirical data demonstrates that the normal banks have the highest LA/D. Though the order of problem and liquidated banks is reverse, we still believe that this variable should belong to the HB group and use it for further analysis.

\subsection{Liquidity variable}


A bank should keep sufficient amount of its assets in liquid assets in case of hugely and abruptly withdrawal of deposits. Liquid assets can be in the forms of cash in vault, current account at other banks, current account at BI, or marketable securities.

\section{Table 18: Average values and ranks of NonII/OI and D/TPF}

Non-interest income/operating icome

\begin{tabular}{lcccc}
\hline \multicolumn{1}{c}{ Aroup } & 1995 & 1996 & \multicolumn{2}{c}{ Average ranks } \\
\hline Normal & $6.77(0.73)$ & $7.03(0.75)$ & 107.25 & 1069.97 \\
Problem & $5.03(0.55)$ & $5.74(0.69)$ & 112.47 & 113.65 \\
Liquidated & $4.25(0.59)$ & $5.36(0.92)$ & 98.26 & 98.38 \\
\hline
\end{tabular}

Deposits/third party funds

\begin{tabular}{lcccc}
\hline \multicolumn{1}{c}{ Average values } & \multicolumn{2}{c}{ Average ranks } \\
\hline Group & 1995 & 1996 & 1995 & 1996 \\
\hline Pormal & $73.95(2.14)$ & $75.82(2.13)$ & 105.94 & 106.26 \\
Liquidated & $80.34(3.06)$ & $82.90(3.05)$ & 105.34 & 112.62 \\
\hline
\end{tabular}

The LA/D variable measures the proportion of deposits which can be repaid promptly if there is a run on that bank. Indeed, the higher this ratio the better bank is. Empirical data demonstrates that the normal banks have the highest LA/D. Though the order of problem and liquidated banks is reverse, we still believe that this variable should belong to the HB group and use it for further analysis.

\subsection{Dependence on affiliates variables}

\section{Loans to affiliates over loans (LtA/L)}

According to Indonesian financial accounting standards, affiliated parties of a bank are defined as

1. Any company that directly or indirectly are controlled or 
under common control of the bank,

2. Any company under control of directors, officers, and close member of the families of directors and officers of the bank,

3. Any company where there is a key management personnel of the bank in it.

It is expected that business relationships between a bank and its affiliates should be impartial in terms of there should be no special advantages gained by affiliates that may be ruining the performance of the bank. There should be no privileges for affiliates to receive a loan approval by ignoring the appropriate assessment of risk involved or paying considerably lower interest for that loans.

We will use loans to affiliates over loans (LtA/L) ratio to measure the portion of loans channelled to affiliates. As it is preferable for a bank not to channel much of its loans to affiliates, LtA/L should belong to the LB group.

Table 19: Average values and ranks of LA/D

\begin{tabular}{lcccc}
\hline & \multicolumn{2}{c}{ Average values } & \multicolumn{2}{c}{ Average ranks } \\
\hline \multicolumn{1}{c}{ Group } & 1995 & 1996 & 1995 & 1996 \\
\hline Normal & $70.61(8.72)$ & $82.99(16.95)$ & 114.55 & 116.66 \\
Problem & $33.43(3.16)$ & $32.34(3.18)$ & 82.89 & 74.32 \\
Liquidated & $38.94(4.87)$ & $36.34(3.39)$ & 92.02 & 90.22 \\
\hline
\end{tabular}

Empirical data seems to support this point of view (see Table 20). Remark that liquidated banks have the highest values of this variable. Liquidated banks are also remarkably aggressive in attracting deposits and in lending (see "Loans growth rate. ..." of Section 2.6). Hence, liquidated banks were attracting deposits and then giving loans but, to great extent, to their affiliates ${ }^{2}$.

\section{Affiliates as sources of funds}

\footnotetext{
${ }^{2}$ The $9.7 \%$ and $7.9 \%$ of total loans given to affiliates may not seem a large portion, but some understanding is that banks tend to mask and understate actual percentage of loans of their affiliates.
} 
We will use deposits from affiliates over deposits (DfA/D) and funds from affiliates over third-party fund (FfA/TPF) to measure the use of affiliates as sources of funds. As long as affiliates do not receive considerably higher interest rate paid to the deposits or funds than market interest rate, they can be a good sources of funds. Hence, these variables can be attributed to the HB group.

Table 20: Average values and ranks of LtA/L

\begin{tabular}{lcccc}
\hline & \multicolumn{2}{c}{ Average values } & \multicolumn{2}{c}{ Average ranks } \\
\hline \multicolumn{1}{c}{ Group } & 1995 & 1996 & 1995 & 1996 \\
\hline Normal & $2.44(0.31)$ & $2.59(0.34)$ & 99.63 & 101.79 \\
Problem & $5.62(3.03)$ & $4.96(3.01)$ & 100.68 & 97.89 \\
Liquidated & $9.71(2.12)$ & $7.90(2.26)$ & 161.06 & 151.30 \\
\hline
\end{tabular}

Empirical data supports this apriori thought, but it is more strongly manifested in FfA/TPF than in DfA/D (see Table 21). Hence we will only use FfA/TPF.

Table 21: Average values and ranks of DfA/D and FfA/TPF

Deposits from affiliates/deposits

\begin{tabular}{lcccc}
\hline \multicolumn{1}{c}{ Average values } & \multicolumn{2}{c}{ Average ranks } \\
\hline Normal & 1995 & 1996 & 1995 & 1996 \\
Problem & $6.21(0.84)$ & $6.66(1.02)$ & 109.15 & 110.99 \\
Liquidated & $5.89(0.98)$ & $4.03(1.28)$ & 91.76 & 92.97 \\
\hline
\end{tabular}

Funds from affiliates/third party funds

\begin{tabular}{lcccc}
\hline \multicolumn{2}{c}{ Average values } & \multicolumn{2}{c}{ Average ranks } \\
\hline \multicolumn{1}{c}{ Group } & 1995 & 1996 & 1995 & 1996 \\
\hline Normal & $11.75(1.44)$ & $11.64(1.50)$ & 114.48 & 116.14 \\
Problem & $3.07(0.99)$ & $4.14(1.27)$ & 78.91 & 79.62 \\
Liquidated & $4.92(1.39)$ & $2.75(0.77)$ & 97.68 & 86.50 \\
\hline
\end{tabular}

The facts that relationship with affiliates can be considered good in terms of sources of fund but can be considered bad in terms of lending activities, 
suggests to develop a new variable which measures nett effects on both kind of relationship. We define net funds of affiliates (NFA) as

$$
\mathrm{NFA}=\mathrm{FfA}-\mathrm{LtA}
$$

and then compare it to the loans.

It is clear that NFA/L variable should have the $\mathrm{HB}$ characteristic as it means that the affiliates do not parasitise on the bank. The empirical data strongly supports that view (see Table 20).

Table 22: Average values and ranks of NFA/L

\begin{tabular}{lcccc}
\hline \multicolumn{1}{c}{ Group } & 1995 & 1996 & \multicolumn{2}{c}{ Average ranks } \\
\hline Normal & $14.90(2.71)$ & $14.50(2.49)$ & 119.28 & 1199.25 \\
Problem & $-1.70(2.94)$ & $0.20(3.11)$ & 76.47 & 83.00 \\
Liquidated & $-3.17(2.29)$ & $-4.26(2.21)$ & 71.14 & 62.72 \\
\hline
\end{tabular}

Therefore we use NFA/L instead of LtA/L, DfA/D, and FfA/TPF in measuring relationship with affiliates for further analysis.

\section{Further Analysis of the Selected Variables}

\subsection{The selected variables}

Previous analysis resulted in selection of the following variables:

The higher the better (HB) group: E/EA, E/L, EBT/SE, IM, LA/D, NFA/L, NII/EA, NII/L,PM, PLL/L, ROE, ROEA.

The lower the better (LB) group: ARCF, COF.

The group of others (O): LGR, LMSI, DGR, DMSI, W/L.

Fiqures 12 and 13 demonstrate the average rank values and the average values of the selected variables for each of three groups of banks respectively. We remark that for normal banks the average rank values of the HB 
variables are remarkably stable at the level about 116 . The average rank values of the $\mathrm{LB}$ variables are stable at the level 99. Note that in inverse ranking, it will give us again 214-99 = 115!

We also remark that we could detect the difference between three groups of banks using the HB and LB variables not only in 1996 but also in 1995, except for ROE amd NII/EA. It means that we could detect the ailing banks two years before their failure.

For the subsequent analysis we will omit variables of the group $\mathrm{O}$ as we believe that these variables will not give significant improvement to the result of analysis on the $\mathrm{HB}$ and $\mathrm{LB}$ variables.

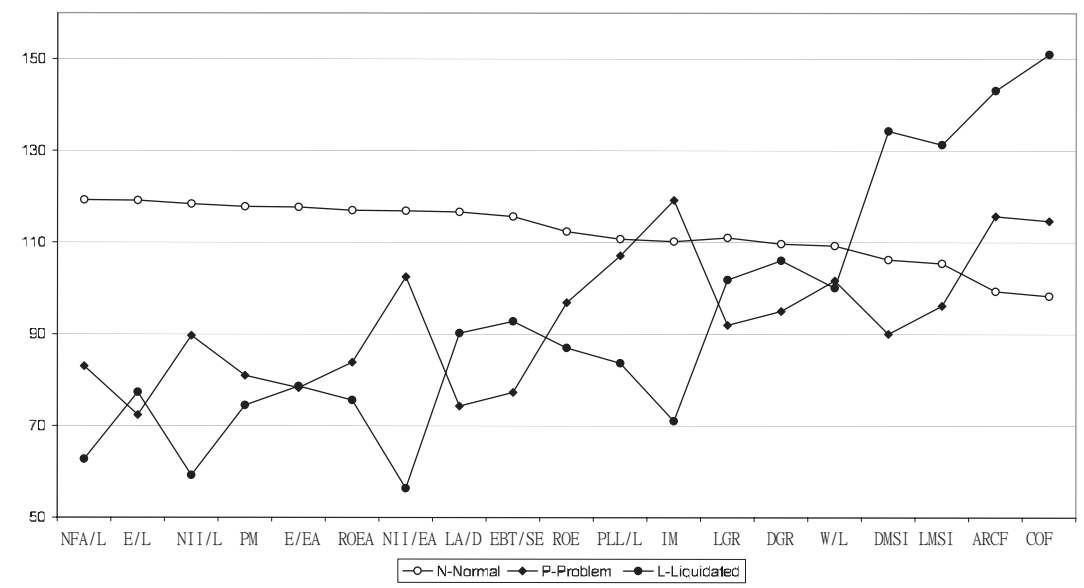

Figure 12: Average ranks of the selected variables for each of the 3 groups of banks in 1996

\subsection{Correlation and factor analysis}

One can suspect that the relative stability of the HB and LB variables is due to high correlation between them. Hence we analyse their correlation using Spearman rank correlation coefficient (see Tables 3.1 and 3.2). We found that indeed many of variables are significantly correlated (values $|\hat{\rho}|>$ 0.167 already speak of significant difference from 0 at $\alpha=0.05$ ). 


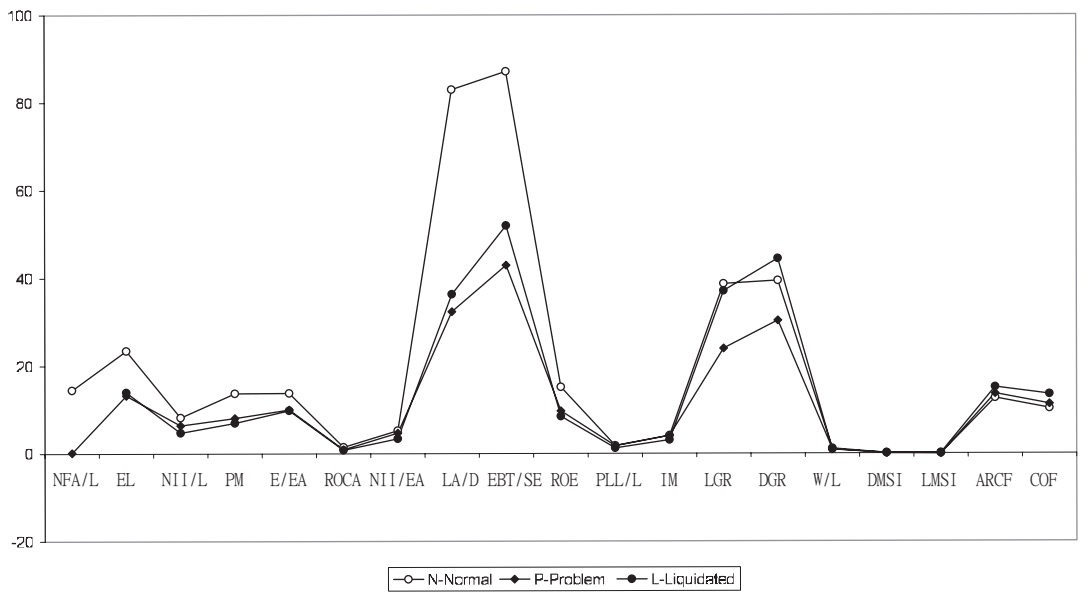

Figure 13: Average values of the selected variables for each of the 3 groups of banks in 1996

Therefore we need to find or create new variables that are possibly uncorrelated. We will do this using factor analysis. Let us recall that we work with the ranks instead of the original values and do not assume normality in our data.

Table 23: Spearman-rank correlation coefficient of the selected variables in 1995

\begin{tabular}{|c|c|c|c|c|c|c|c|c|c|c|c|c|c|c|}
\hline & Variable & 1 & 2 & 3 & 4 & 5 & 6 & 7 & 8 & 9 & 10 & 11 & 12 & 13 \\
\hline 1 & $\overline{\mathrm{ARCF}}$ & & & & & & & & & & & & & \\
\hline 2 & $\mathrm{COF}$ & .960 & & & & & & & & & & & & \\
\hline 3 & $\mathrm{E} / \mathrm{EA}$ & 198 & .213 & & & & & & & & & & & \\
\hline 4 & $\mathrm{E} / \mathrm{L}$ & .022 & .043 & .860 & & & & & & & & & & \\
\hline 5 & $\mathrm{EBT} / \mathrm{SE}$ & -.386 & -.371 & .204 & .224 & & & & & & & & & \\
\hline 6 & IM & .093 & -.166 & -.032 & -.036 & -.017 & & & & & & & & \\
\hline 7 & $\mathrm{LA} / \mathrm{D}$ & -.491 & -.447 & .071 & 417 & .282 & -.143 & & & & & & & \\
\hline 8 & NFA/L & -.116 & -.061 & .209 & 179 & .207 & -.184 & .175 & & & & & & \\
\hline 9 & NII/EA & .416 & .404 & .561 & .474 & -.571 & .023 & -.141 & -.023 & & & & & \\
\hline 10 & NII/L & .066 & -.104 & .287 & .466 & .051 & .647 & .263 & -.022 & .264 & & & & \\
\hline 11 & PM & -.441 & -.496 & .256 & .272 & .890 & .250 & .260 & . 126 & -.462 & .312 & & & \\
\hline 12 & PLL/L & -.326 & -.383 & -.099 & -.029 & .292 & .215 & . 196 & .018 & -.198 & .242 & .359 & & \\
\hline 13 & $\mathrm{ROE}$ & -.310 & -.420 & -.346 & -.288 & .592 & .438 & .062 & -.041 & -.780 & .209 & .676 & 411 & \\
\hline 14 & ROEA & -.199 & -.300 & .311 & .296 & .803 & .393 & . 126 & .069 & -.370 & .411 & .924 & .310 & .702 \\
\hline
\end{tabular}


Table 24: Spearman-rank correlation coefficient of the selected variables in 1996

\begin{tabular}{|llrrrrrrrrrrrrr|}
\hline & Variable & 1 & 2 & 3 & 4 & 5 & 6 & 7 & 8 & 9 & 10 & 11 & 12 & 13 \\
\hline 1 & ARCF & & & & & & & & & & & & & \\
2 & COF & .961 & & & & & & & & & & & \\
3 & E/EA & .081 & .092 & & & & & & & & & & \\
4 & E/L & -.041 & -.030 & .887 & & & & & & & & & \\
5 & EBT/SE & -.445 & -.447 & .224 & .287 & & & & & & & & \\
6 & IM & -.011 & -.251 & -.036 & -.037 & .077 & & & & & & & \\
7 & LA/D & -.534 & -.507 & .147 & .452 & .372 & -.085 & & & & & & \\
8 & NFA/L & -.155 & -.104 & .150 & .152 & .193 & -.195 & .191 & & & & & \\
9 & NII/EA & .049 & -.148 & .301 & .275 & .182 & .797 & .003 & -.145 & & & & \\
10 & NII/L & -.069 & -.229 & .294 & .483 & .225 & .642 & .389 & -.084 & .833 & & & \\
11 & PM & -.521 & -.579 & .241 & .304 & .915 & .308 & .374 & .120 & .430 & .434 & & & \\
12 & PLL/L & -.331 & -.417 & -.033 & .040 & .399 & .326 & .261 & .027 & .372 & .363 & .477 & & \\
13 & ROE & -.382 & -.491 & -.252 & -.171 & .702 & .476 & .171 & .045 & .382 & .338 & .787 & .460 & \\
14 & ROEA & -.311 & -.410 & .285 & .311 & .872 & .423 & .247 & .080 & .546 & .491 & .947 & .451 & .795 \\
\hline
\end{tabular}

We choose principal component method to estimate factor coefficients. Then we rotate initial solution using Varimax rotation method to get more interpretable factors.

The eigen-values of covariance matrix (Table 25) suggest that after the seventh factor they are relatively small and there is not much variation left which can be explained. The first seven factors could explain about $96 \%$ of variation.

\section{Table 25: The eigen-values of covariance matrix of} the selected variables

\begin{tabular}{|c|c|c|c|c|c|c|c|c|c|c|c|c|c|c|}
\hline Factor & 1 & 2 & 3 & 4 & 5 & 6 & 7 & 8 & $\overline{9}$ & 10 & 11 & 12 & 13 & 14 \\
\hline Eigen-value & 5.24 & 2.64 & 2.21 & 1.38 & .84 & .64 & .60 & .18 & .11 & .08 & .04 & .02 & .02 & .01 \\
\hline $\begin{array}{l}\text { Cumulative } \\
\% \text { of variation } \\
\text { explained }\end{array}$ & 37.4 & 56.3 & 72.1 & 81.9 & 87.9 & 92.5 & 96.7 & 98.0 & 98.7 & 99.3 & 99.6 & 99.8 & 99.9 & 100.0 \\
\hline \multicolumn{15}{|l|}{ in 1995} \\
\hline Factor & 1 & 2 & 3 & 4 & 5 & 6 & 7 & 8 & 9 & 10 & 11 & 12 & 13 & 14 \\
\hline Eigen-value & 4.75 & 2.87 & 1.99 & 1.54 & .88 & .74 & .67 & .19 & .15 & .10 & .05 & .04 & .03 & .01 \\
\hline $\begin{array}{l}\text { Cumulative } \\
\% \text { of variation } \\
\text { explained }\end{array}$ & 33.9 & 54.4 & 68.7 & 79.7 & 86.0 & 91.2 & 96.0 & 97.4 & 98.4 & 99.1 & 99.5 & 99.8 & 100.0 & 100.0 \\
\hline
\end{tabular}

We would not rely on "formal" factor analysis and would be reluctant to accept any emerging "factors" without clear intuitive meaning. How- 
ever, almost all of these first seven factors have clear economical meaning (see Tables 2.5 and 2.6). In particular, three of them (Factors 5-7) depend basically on one of our selected variables: LA/D (liquidity aspect), NFA/L (dependency on affiliates aspect), and PLL/L (security of asset aspect) respectively. It means that these three variables are already almost independent "factors".

Table 26: Rotated factor coefficients of the selected variables in 1996

\begin{tabular}{lrrrrrrr}
\hline & & \multicolumn{7}{c}{ Factor } \\
Variable & 1 & 2 & 3 & 4 & 5 & 6 & 7 \\
\hline $\mathbf{R}_{\mathrm{ARCF}}$ & -.24247 & .11880 & .05863 & $\mathbf{. 9 3 4 3 2}$ & -.17702 & -.02528 & -.08604 \\
$\mathbf{R}_{\mathrm{COF}}$ & -.27261 & -.10829 & .10346 & $\mathbf{. 9 2 8 6 6}$ & -.14744 & -.00221 & -.11579 \\
$\mathbf{R}_{\mathrm{E} / \mathrm{EA}}$ & .07194 & .06335 & $\mathbf{. 9 7 6 4 3}$ & .08699 & -.07597 & .03724 & -.02667 \\
$\mathbf{R}_{\mathrm{E} / \mathrm{L}}$ & .08701 & .09900 & $\mathbf{. 9 1 8 4 4}$ & .03552 & .31744 & .01699 & -.01619 \\
$\mathbf{R}_{\mathrm{EBT} / \mathrm{SE}}$ & $\mathbf{. 9 3 1 5 3}$ & -.06725 & .14337 & -.18404 & .11524 & .06129 & .12059 \\
$\mathbf{R}_{\mathrm{IM}}$ & .15161 & $\mathbf{. 9 1 0 2 5}$ & -.14563 & -.08319 & -.14794 & -.07973 & .04992 \\
$\mathbf{R}_{\mathrm{LA} / \mathrm{D}}$ & .13269 & -.02882 & .15569 & -.36666 & $\mathbf{. 8 8 0 8 0}$ & .06515 & .08866 \\
$\mathbf{R}_{\mathrm{NFA} / \mathrm{L}}$ & .05060 & -.18950 & .04461 & -.02069 & .04161 & $\mathbf{. 9 7 8 0 2}$ & .00377 \\
$\mathbf{R}_{\mathrm{NII} / \mathrm{L}}$ & .15942 & $\mathbf{. 8 1 8 8 5}$ & .22391 & .03552 & .41926 & -.10567 & .10970 \\
$\mathbf{R}_{\mathrm{NII} / \mathrm{EA}}$ & .21250 & $\mathbf{. 9 0 2 4 8}$ & .18339 & .07749 & -.07041 & -.11972 & .14055 \\
$\mathbf{R}_{\mathrm{PLL} / \mathrm{L}}$ & .28709 & .22166 & -.05420 & -.18477 & .09153 & .00472 & $\mathbf{. 9 0 6 4 0}$ \\
$\mathbf{R}_{\mathrm{PM}}$ & $\mathbf{. 8 9 7 7 4}$ & .19417 & .14151 & -.29823 & .08476 & -.00027 & .12772 \\
$\mathbf{R}_{\mathrm{ROE}}$ & $\mathbf{. 8 0 8 5 5}$ & .31084 & -.38978 & -.17504 & .03989 & .02797 & .09816 \\
$\mathbf{R}_{\mathrm{ROEA}}$ & $\mathbf{. 9 1 1 1 4}$ & .31849 & .15679 & -.09505 & .00814 & -.00656 & .10916 \\
\hline
\end{tabular}

Notice that the first factor is dominantly associated with four variables of the same group of earning, productivity and efficiency. These variables are ranks of ROE, ROEA, EBT/SE and PM. Most natural outcome of this situation is to create one single new variable which will reflect efficiency in earning and productivity of a bank. Hence we define

$$
\mathrm{C} 1=\left(\mathbf{R}_{\mathrm{ROE}}+\mathbf{R}_{\mathrm{ROEA}}+\mathbf{R}_{\mathrm{EBT} / \mathrm{SE}}+\mathbf{R}_{\mathrm{PM}}\right) / 4
$$

for that purpose.

Similarly, the third factor in 1996 and the second factor in 1995 are associated with RE/EA and RE/L variables. Both E/EA and E/L variables 
can be used to measure capital adequacy of a bank. Hence we define

$$
\mathrm{C} 2=\left(\mathbf{R}_{\mathrm{E} / \mathrm{EA}}+\mathbf{R}_{\mathrm{E} / \mathrm{L}}\right) / 2
$$

to represent capital adequacy aspect.

Table 27: Rotated factor coefficients of the selected variables in 1995

\begin{tabular}{|lrrrrrrr|}
\hline & \multicolumn{7}{c|}{ Factor } \\
Variable & 1 & 2 & 3 & 4 & 5 & 6 & 7 \\
\hline $\mathbf{R}_{\mathrm{ARCF}}$ & -.19549 & .13838 & $\mathbf{. 9 3 1 0 3}$ & .13970 & -.19510 & -.02086 & -.09990 \\
$\mathbf{R}_{\mathrm{COF}}$ & -.22909 & .16698 & $\mathbf{. 9 3 4 3 6}$ & -.10290 & -.13649 & -.01030 & -.11703 \\
$\mathbf{R}_{\mathrm{E} / \mathrm{EA}}$ & .15315 & $\mathbf{. 9 4 4 5 7}$ & .16584 & .00380 & -.06705 & .07113 & -.06290 \\
$\mathbf{R}_{\mathrm{E} / \mathrm{L}}$ & .11377 & $\mathbf{. 8 9 0 5 2}$ & .05152 & .10692 & .34725 & .01813 & -.04489 \\
$\mathbf{R}_{\mathrm{EBT} / \mathrm{SE}}$ & $\mathbf{. 9 2 8 2 1}$ & .05840 & -.15070 & -.14693 & .11545 & .08783 & .09173 \\
$\mathbf{R}_{\mathrm{IM}}$ & .15171 & -.09658 & -.02622 & $\mathbf{. 9 1 2 2 6}$ & -.21166 & -.10696 & .03999 \\
$\mathbf{R}_{\mathrm{LA} / \mathrm{D}}$ & .07905 & .10341 & -.31901 & -.00102 & $\mathbf{. 9 1 4 1 3}$ & .06259 & .06490 \\
$\mathbf{R}_{\mathrm{NFA} / \mathrm{L}}$ & .04066 & .05660 & -.00816 & -.11109 & .05154 & $\mathbf{. 9 8 9 7 8}$ & -.01289 \\
$\mathbf{R}_{\mathrm{NII} / \mathrm{L}}$ & .10013 & .28418 & .07493 & $\mathbf{. 8 4 9 8 9}$ & -.29098 & -.04358 & .11595 \\
$\mathbf{R}_{\mathrm{NII} / \mathrm{EA}}$ & -.61667 & .70084 & .17997 & .16142 & .13798 & -.02429 & .00306 \\
$\mathbf{R}_{\mathrm{PLL} / \mathrm{L}}$ & .20741 & -.09488 & -.17538 & .11899 & .06009 & .01447 & $\mathbf{. 9 4 7 3 0}$ \\
$\mathbf{R}_{\mathrm{PM}}$ & $\mathbf{. 9 1 6 2 0}$ & .12086 & -.26983 & .15172 & .03884 & .00814 & .10242 \\
$\mathbf{R}_{\mathrm{ROE}}$ & $\mathbf{. 7 3 7 5 7}$ & -.51083 & -.11698 & .31227 & .01056 & -.03017 & .15615 \\
$\mathbf{R}_{\mathrm{ROEA}}$ & $\mathbf{. 9 1 3 9 8}$ & .14868 & -.04514 & .30217 & -.03500 & .02223 & .07630 \\
\hline
\end{tabular}

We also create

$$
\mathrm{C} 3=\left(\mathbf{R}_{\mathrm{IM}}+\mathbf{R}_{\mathrm{NII} / \mathrm{L}}\right) / 2
$$

as both $\mathbf{R}_{\mathrm{IM}}$ and $\mathbf{R}_{\mathrm{NII} / \mathrm{L}}$ variables are dominant part in the same factor both in 1996 and in 1995. This new variable can be interpreted as a measure of the interest gap of a bank.

$\mathbf{R}_{\mathrm{ARCF}}$ and $\mathbf{R}_{\mathrm{COF}}$ are found to be a pair of variables responsible in the same factor both in 1996 and in 1995. From the definition of ARCF and COF (see Section 2.6) we recognize that ARCF variable structurally contains information conveyed by COF variable and in fact they are highly correlated. It means that it is unnecessary and inefficient to keep both variables, therefore we dropped $\mathbf{R}_{\mathrm{COF}}$ variable. 
Finally, we observed that RNII/EA behaviour is unstable. It is, jointly with $\mathbf{R}_{\mathrm{IM}}$ and $\mathbf{R}_{\mathrm{NII} / \mathrm{L}}$, associated with the second factor in 1996 , but it is, jointly with $\mathbf{R}_{\mathrm{E} / \mathrm{EA}}$ and $\mathbf{R}_{\mathrm{E} / \mathrm{L}}$, associated with the second factor in 1995 . As this kind of instability characteristic may not be useful for prediction purpose, we decided to drop this variable.

\subsection{New variables - the final choice and classification}

We redo factor analysis using $\mathbf{R}_{\mathrm{C} 1}, \mathbf{R}_{\mathrm{C} 2}, \mathbf{R}_{\mathrm{C} 3}, \mathbf{R}_{\mathrm{ARCF}}, \mathbf{R}_{\mathrm{LA} / \mathrm{D}}, \mathbf{R}_{\mathrm{NFA} / \mathrm{L}}$,

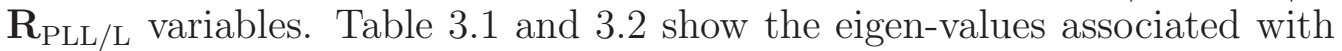
each factor in 1996 and 1995 respectively. Notice that objective of factor analysis at this stage is to check the independence of characteristic variables as factors, and not to evaluate their explainability of variation as it is quite clear from the previous section that these seven variables were explaining about $96 \%$ of original variation.

\section{Table 28: The eigen-values of covariance matrix of the final variables}

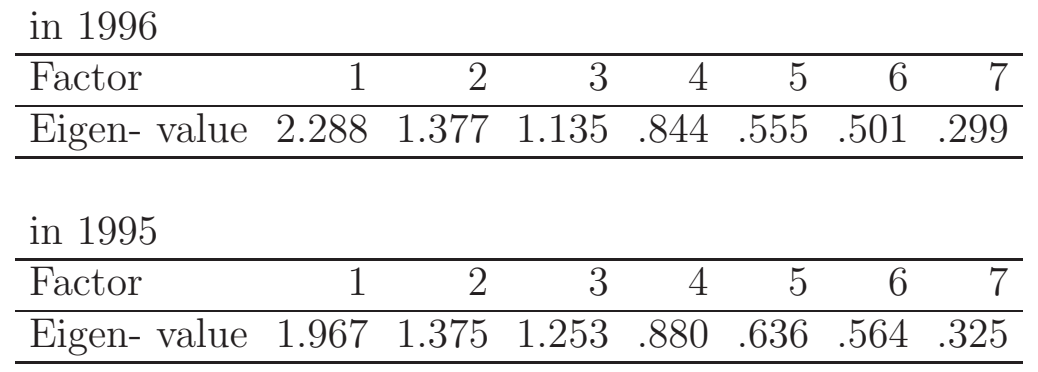

It is clearly demonstrated in Tables 29 and 30 that for each factor there is only single variable associated with it. It means that these seven variables can be considered practicals as independent factors, or in other words, variables are now equal to factors.

The three new variables, C1, C2 and C3 each has sufficient discriminatory power (see Table 31).

Figures 14 and 15 show the average ranks of the final variables of each group of banks in 1996 and 1995 respectively. Now it is indeed easier to separate out normal banks from ailing banks. (compare to Figure 11 in 
Section 2)

Table 29: Rotated factor coefficients of the final variables in 1996

\begin{tabular}{|lrrrrrrr|}
\hline & \multicolumn{7}{c|}{ Factor } \\
Variable & 1 & 2 & 3 & 4 & 5 & 6 & 7 \\
\hline $\mathbf{R}_{\mathrm{C} 1}$ & 0.05243 & 0.22173 & 0.02954 & 0.19124 & 0.09263 & $\mathbf{0 . 9 2 8 4 7}$ & -0.20002 \\
$\mathbf{R}_{\mathrm{C} 2}$ & $\mathbf{0 . 9 8 6 6 5}$ & -0.02590 & 0.03221 & 0.06849 & 0.12179 & 0.04333 & 0.05834 \\
$\mathbf{R}_{\mathrm{C} 3}$ & 0.07609 & 0.16916 & -0.14880 & $\mathbf{0 . 9 5 2 4 1}$ & 0.05714 & 0.17685 & 0.04282 \\
$\mathbf{R}_{\mathrm{ARCF}}$ & 0.07330 & -0.13551 & -0.03456 & 0.04788 & -0.27576 & -0.20100 & $\mathbf{0 . 9 2 5 3 8}$ \\
$\mathbf{R}_{\mathrm{LA} / \mathrm{D}}$ & 0.14319 & 0.10401 & 0.06489 & 0.06133 & $\mathbf{0 . 9 4 0 4 0}$ & 0.08837 & -0.26183 \\
$\mathbf{R}_{\mathrm{NFA} / \mathrm{L}}$ & 0.03235 & -0.00288 & $\mathbf{0 . 9 8 8 2 9}$ & -0.13229 & 0.05690 & 0.02462 & -0.02983 \\
$\mathbf{R}_{\mathrm{PLL} / \mathrm{L}}$ & -0.02982 & $\mathbf{0 . 9 4 8 2 4}$ & -0.00358 & 0.17137 & 0.10288 & 0.20865 & -0.12823 \\
\hline
\end{tabular}

Table 30: Rotated factor coefficients of the final variables in 1995

\begin{tabular}{|lrrrrrrr|}
\hline & & \multicolumn{7}{c|}{ Factor } \\
Variable & 1 & 2 & 3 & 4 & 5 & 6 & 7 \\
\hline $\mathbf{R}_{\mathrm{C} 1}$ & 0.05453 & 0.03937 & 0.17201 & 0.15528 & 0.02113 & $\mathbf{0 . 9 5 6 6 8}$ & -0.16156 \\
$\mathbf{R}_{\mathrm{C} 2}$ & 0.10943 & $\mathbf{0 . 9 8 1 0 1}$ & -0.06263 & 0.08412 & 0.05620 & 0.03602 & 0.10099 \\
$\mathbf{R}_{\mathrm{C} 3}$ & 0.02349 & 0.08673 & 0.10444 & $\mathbf{0 . 9 7 1 0 2}$ & -0.09752 & 0.14804 & 0.08193 \\
$\mathbf{R}_{\mathrm{ARCF}}$ & -0.26168 & 0.12159 & -0.14402 & 0.09494 & -0.01976 & -0.17775 & $\mathbf{0 . 9 2 4 6 6}$ \\
$\mathbf{R}_{\mathrm{LA} / \mathrm{D}}$ & $\mathbf{0 . 9 5 8 0 5}$ & 0.11995 & 0.07717 & 0.02636 & 0.05994 & 0.05295 & -0.23387 \\
$\mathbf{R}_{\mathrm{NFA} / \mathrm{L}}$ & 0.05416 & 0.05424 & -0.01381 & -0.0911 & $\mathbf{0 . 9 9 2 4 7}$ & 0.01878 & -0.01696 \\
$\mathbf{R}_{\mathrm{PLL} / \mathrm{L}}$ & 0.07663 & -0.06553 & $\mathbf{0 . 9 6 6 4 5}$ & 0.10605 & -0.01514 & 0.16719 & -0.12797 \\
\hline
\end{tabular}

Therefore the final choice of variables are the following:

1. C1 - efficiency in productivity and earning

2. C2 - capital adequacy

3. C3 - interest gap

4. ARCF - credibility

5. LA/D - liquidity

6. NFA/L - dependence on affiliates

7. PLL/L - security of earning asset

\section{Conclusion}

Though published financial statement of a bank contains limited information, still we could exploit it to discriminate normal, problem, and liquidated banks by using the rank values of carefully selected variables: 
E/EA, E/L, EBT/SE, IM, LA/D, NFA/L, NII/EA, NII/L, PM, PLL/L, ROE, ROEA, ARCF, and COF. The first twelve of these variables have the higher the better characteristic, while the last two have the lower the better characteristic.

Table 31: Average value and discriminatory power of the new variables

\begin{tabular}{|c|c|c|c|c|c|}
\hline \multirow[b]{2}{*}{ Year } & \multicolumn{4}{|c|}{ Group } & \multirow[b]{2}{*}{$\begin{array}{l}\mathrm{p} \text {-value for } \\
\text { testing the difference } \\
\text { between groups }\end{array}$} \\
\hline & Variable & $\mathrm{N}$ & $\mathrm{P}$ & $\mathrm{L}$ & \\
\hline \multirow{3}{*}{1996} & $\mathrm{C} 1$ & 116.45 & 82.61 & 80.60 & .0012 \\
\hline & $\mathrm{C} 2$ & 118.96 & 74.20 & 76.16 & .0000 \\
\hline & C3 & 115.15 & 103.48 & 61.10 & .0002 \\
\hline \multirow{3}{*}{1995} & C1 & 115.15 & 84.61 & 86.00 & .0068 \\
\hline & $\mathrm{C} 2$ & 119.16 & 71.89 & 77.94 & .0000 \\
\hline & C3 & 112.34 & 115.82 & 62.28 & .0006 \\
\hline
\end{tabular}

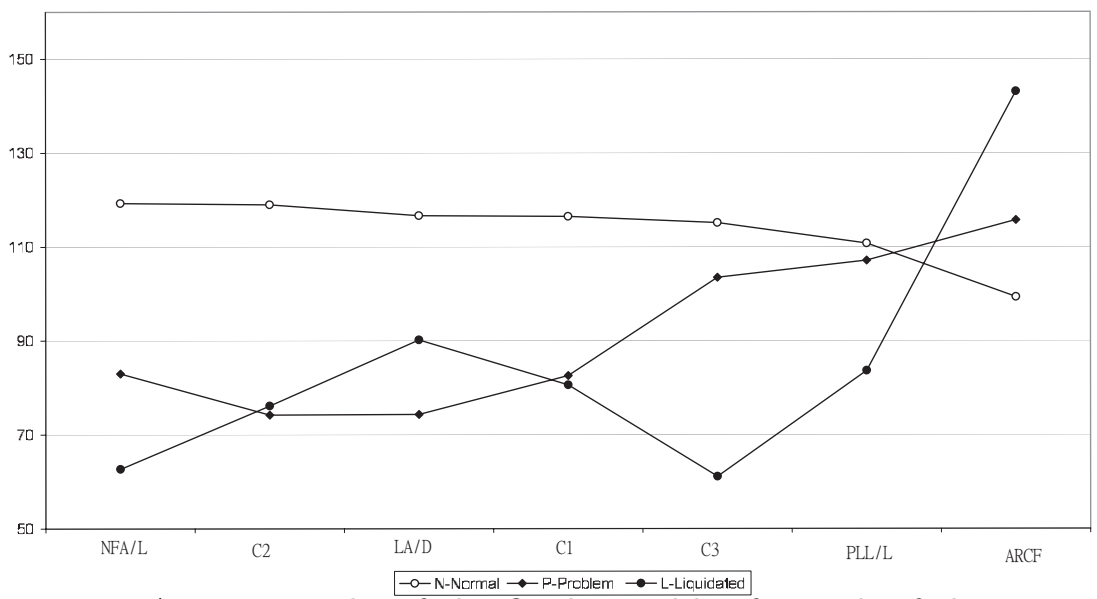

Figure 14: Average ranks of the final variables for each of the 3 gropus of banks in 1996

The ranks of E/EA, E/L, EBT/SE, IM, LA/D, NFA/L, NII/L, PM, PLL/L, ROEA, ARCF, and COF.could discriminate significantly two years 


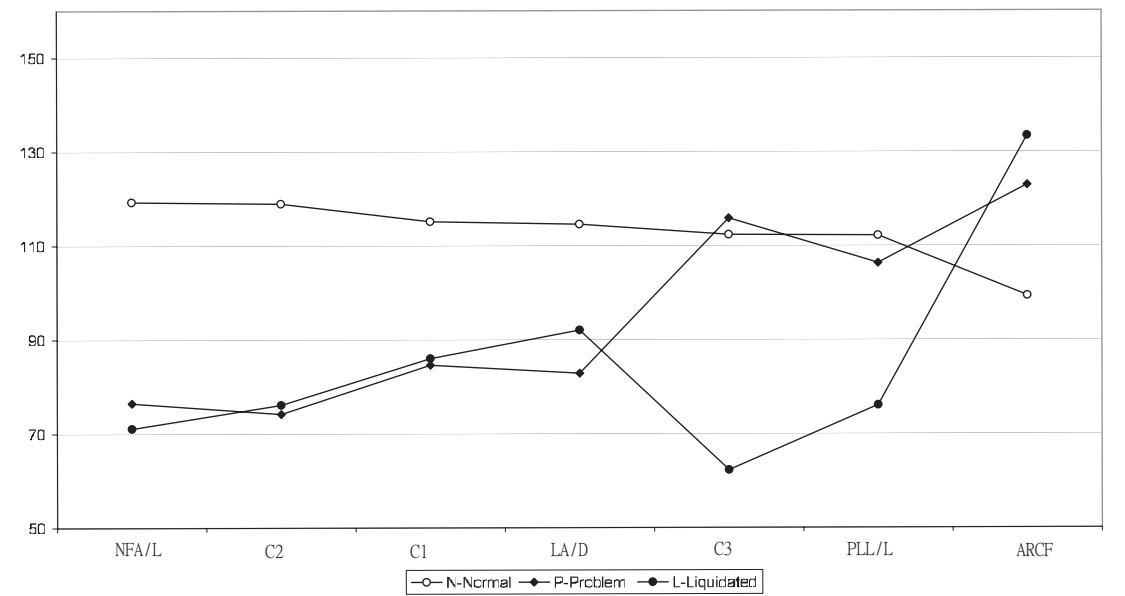

Figure 15: Average ranks of the final variables for each of the 3 gropus of banks in 1995

before failure, while ROE and NII/EA could discriminate one year before failure.

It is confirmed that there are seven stable and independent aspects of financial structure and performance of a bank and their associated variables to measure with:

1. efficiency in productivity and earning (average rank values of EBT/SE, PM, ROE and ROEA),

2. capital adequacy (average rank values of $\mathrm{E} / \mathrm{EA}$ and $\mathrm{E} / \mathrm{L}$ ),

3. interest gap (average rank values of IM and NII/L),

4. credibility (rank values of $\mathrm{ARCF}$ ),

5. liquidity (rank values of LA/D),

6. dependence on affiliates (rank values of NFA/L), and

7. security of earning assets.(rank values of PLL/L).

\section{References}

Baayen, R.H. (2001) Word frequency distribution. Kluwer Academic Publishers, Dordrecht/Boston/London. 
Gorsuch, R. L. (1983), Factor Analysis, 2nd ed., Lawrence Erlbaum Assoc., New Jersey.

Hajek, J. and Sidak, Z. (1967), Theory of rank tests, Academic Press.

Hempel, G. H., Simonson, D. G. and Coleman, A.B. (1994), Bank Management: Text and Cases, 4th ed., John Wiley \& Sons, New York

Jolliffe, I. T. (1986), Principal Component Analysis, Springer-Verlag, New York.

Judijanto, L. and Khmaladze, E. V. (2003), Analysis of Bank Failure Using Published Financial Statements: The Case of Indonesia (Part 1), Journal of data Science, 1, no. 2, 199-230.

Judijanto, L. and Khmaladze, E. V. (1998), Analysis of bank failure using published financial statements: the case of Indonesia, UNSW, Report S98-17.

Khmaladze, E. (2001) “Zipf's Law", Encyclopaedia of Mathematics, Supplement III, Kluwer Academic Publishers, Dordrecht/Boston/London, 460-463.

Saunders, A. (1994). Financial Institutions Management: A Modern Perspective, Richard D. Irwin, Illinois

Siegel, S. and Castellan, N. J. (1988), Nonparametric Statistics for the Behavioral Sciences, 2nd ed., McGraw-Hill, New York.

White, G. I., Sondhi, A. C., and Fried, D. (1997), The Analysis and Use of Financial Statements, 2nd ed., John Wiley \& Sons, New York.

Received December 20, 2001; accepted June 30, 2002

Loso Judijanto

Perumahan Harapan Indah

Jl. Anggur IV Blok XG 8

Bekasi 17131

Indonesia

losoj@mweb.co.id

Easte V. Khmaladze

Chair in Statistics

School of Mathematical and Computing Sciences 
L. Judijanto and E. V. Khmaladze

Victoria University of Wellington

PO Box 600, Wellington, NZ

e-mail: estate.khmaladze@mcs.vuw.ac.nz 